Complementary

Medicine Research

Practice|Methods|Perspectives
Editorial

Complement Med Res 2018;25:364-366

DOI: $10.1159 / 000495129$
Published online: November 23, 2018

\title{
We Need a New Narrative: Agents instead of Patients
}

\author{
Harald Walach \\ Department of Pediatric Gastroenterology, Medical University Poznan, Poznan, Poland
}

The definition of postmodernity is the failure of the 'big narratives', mainly the big narrative of religion and religious salvation [1], with the result of a thoroughly secular culture [2], at least in our Western societies. Many people think that this yields a society without any rules and with a 'philosophy to go'. In fact, it seems that at least in medicine a different narrative has taken over. It is the narrative of the post-modern physical repair shop which can replace broken parts - like hips, knees, hearts - and uses pharmacological fixes for complex internal situations, thus improving the condition of patients [3]. This is a subtheme of the larger narrative of the scientific-rational program to improve our living conditions, at least materially, and as such has achieved a lot, no doubt. Life expectancy is rising, morbidity is compressed in some areas, at least to some degree, at the end of life. Infant and childhood deaths are on the decline [4]. Hence, the figures seem to support this narrative of improvements for patients through scientific means. Modern science has taken over the job of religion to provide a background narrative for our post-modern minds, if not hearts.

In medicine, this narrative is the patient story. People with diseases are called patients, and they are supposed to be fixed by evidence-based methods of treatment that have undergone rigid testing. No? Well, partially. The point I wish to make is: this narrative is only useful for some cases, but not for others. It is derived from the grand narrative of improving living conditions and is mainly applicable to standard problems in medicine which arose at the beginning of the medical-pharmaceutical era that can be roughly equated with the demands for emergency medicine by the big wars and the big epidemics of the $19^{\text {th }}$ and $20^{\text {th }}$ century. In emergency medicine, we have the biggest historical victories: over pain (through the discovery of morphine and related substances), over infectious diseases (through the discovery of hygiene, vaccination, and antibiosis), as well as over acute emergencies and accidents (through the development of surgical techniques). At this point, medicine started to extend the remit of its narrative from the acute emergency in a helpless patient to all other medical problems, diseases, and illnesses, and this is where the problem originated.

The major challenges of our post-modern era are not necessarily analyzable in the same way. They are not about medical emergencies, where a repair-shop mentality can be set to work to fix broken limbs, hearts, and immune systems. Most of our modern-day problems are chronic, complex, functional, psychosomatic, or psychosocial in nature [5]. And more than $70 \%$ of the 'patient' load in a general practitioner's consulting room are of a functional and complex kind and cannot be dealt with through such a narrative of patients in need of repair [6, 7]. Typically, the contemporary big killers in our societies - coronary artery disease with myocardial infarction and stroke, cancer, and the big threats like inflammatory neurodegenerative diseases, such as dementias, Alzheimer's, Parkinson's, or

\section{KARGER}

() 2018 S. Karger GmbH, Freiburg

Fax +497614520714
Prof. Dr. Harald Walach

Department of Pediatric Gastroenterology

Medical University Poznan

ul. Szpitalna 27/33, 60-572 Poznan, Poland

hwalac@gmail.com 
other inflammatory conditions [8-10] - very often resist treatments that follow this narrative, or rather, they can only be caged in and treated symptomatically, but not causally, using such a narrative as a guide. Why? Well, because they are largely conditioned through lifestyle choices, social and working conditions [11, 12], and a complex mix of factors that do not allow for a single-cause treatment $[10,13]$. Thus, treatment regimes that follow the patientrepair narrative will likely only fix symptoms superficially and help with symptom relief, often at the cost of more protracted and severe follow-up problems.

What should we do? I suggest, it is time for a different narrative: the agent narrative $[14,15]$. Human beings only become patients when they are incapable of helping themselves and when they are dependent on medical interventions for life-saving measures. In that case, the conceptual abstraction of a patient works well: he or she is then a passive recipient of medical treatment. In most cases, however, humans play an active role: they make choices, e.g., regarding what they eat and do not eat, drink and do not drink, how they spend their leisure time, what information they expose themselves to, and whether or not to take their medications. Hence, they could be seen as agents [16]. Yet, people are mostly treated as 'patients', as passive and patient recipients of whatever salvation our modern culture has in stock for them, from television programs to the most recent electronic gadgets. But by ignoring the agency of patients, medicine is actually forfeit of the most important element in cure: the active participation, decision, and will of 'patients', sorry, agents. Only if we recognize that human beings are agents in the first place, there will be a change in outlook, therapy, and possibly morbidity. It is the lifestyle choices people make, how they are interrelated socially, what support networks they have built up, what type of activities they follow in their leisure time, whether they are physically active or not, whether they do some kind of consciousness practice such as meditation, mindfulness or stress management, it is all those activities of conscious agents that will determine, at least to a large degree, when morbidity and what type of disease will set in. It is not that we will be able to prevent death and disease. However, we might be able to compress morbidity into a short window just before death and over and above have healthy-aging populations. For that to happen, we have to change the narrative, at least for all those who do not seek emergency treatment, from patients to agents. Only then will it be possible to motivate people to make lifestyle choices that support them in their health and their lives. Furthermore, this will likely make a lot of medical interventionism superfluous.
To give an example: sleeplessness can be seen as a medical condition of a patient, which will then likely be treated somehow pharmacologically, with all the known side effects. In contrast, it can also be regarded as the condition of an agent and, consequently, would have to be analyzed differently. What is the reason for this hyperactivity? Are there lifestyle choices, such as caffeine-containing beverages, untoward lightening conditions, overstimulation, stress at work or in the family that keep the person awake? If so, what exactly are they, and how can they be changed. The important point of departure here is that it is the patient, sorry, agent, who has to make the changes, not the doctor or therapist. The doctor also changes: from the one who has the solution for a patient to a companion through life helping the agent to see new solutions. In many cases, this would not necessarily have to be a medical doctor. New professions we do not even have yet could play this role, 'life coaches' for instance, who have a mixed portfolio of medical and psychological knowledge - more psychological knowledge than a standard doctor and more medical knowledge than a standard psychotherapist or counselor.

Thus, the challenge will be to install this new narrative within a professional system that is completely geared to the old patient narrative. Here, complementary and alternative medicine (CAM) is an important trail blazer, without even knowing it. For a lot of methods within CAM are actually banking on the agent narrative, seeing themselves as generically regulating a psychophysical system that has gone out of balance. It is the system's activity in the first place that creates health or disease, and the task of the therapy is to stimulate the system back into a health-producing or self-healing mode $[17,18]$. Having said this, it would be a bad mistake for CAM and its methods to conform themselves to the grand patient narrative of conventional medicine [19]. Rather, it would be productive to make this difference more pronounced, because this is how a change towards an agent narrative is going to be brought about. By saying out loud, and acting out proud: 'we work with agents, and we will accompany them through life - we do not treat patients'. Agents, instead of patients, this is the new narrative we need.

\section{Disclosure Statement}

I have no conflict of interest.

\section{References}

1 Lyotard J-F: La Condition Postmoderne. Paris, Editions de Minuit, 1979.

2 Taylor C: A Secular Age. Cambdrige, Harvard University Press, 2007.

3 Loughlin M, Lewith G, Falkenberg T: Science, practice and mythology: a definition and examination of the implications of scientism in medicine. Health Care Anal 2013;21:130-145.
4 Wang H, Dwyer-Lindgren L, Lofgren KT, Rajaratnam JK, Marcus JR, Levin-Rector A, Levitz CE, Lopez AD, Murray CJ: Age-specific and sex-specific mortality in 187 countries, 1970-2010: a systematic analysis for the Global Burden of Disease Study 2010. Lancet 2012;380: 2071-2094.
5 Global Burden of Disease Study 2013 Collaborators: Global, regional, and national incidence, prevalence, and years lived with disability for 301 acute and chronic diseases and injuries in 188 countries, 1990-2013: a systematic analysis for the Global Burden of Disease Study 2013. Lancet 2015;386:743-800 
6 Laux G, Kuehlein T, Rosemann T, Szecsenyi J: Co- and multimorbidity patterns in primary care based on episodes of care: results from the German CONTENT project. BMC Health Serv Res 2008;8:14.

7 Glynn LG, Valderas JM, Healy P, Burke E, Newell J, Gillespie P, Murphy AW: The prevalence of multimorbidity in primary care and its effect on health care utilization and cost. Fam Pract 2011;28:516-523.

8 Rizzuto D, Fratiglioni L: Lifestyle factors related to mortality and survival: a mini-review. Gerontology 2014;60:327-335.

$\checkmark$ Loef M, Walach $\mathrm{H}$ : The combined effects of healthy lifestyle behaviors on all cause mortality: a systematic review and meta-analysis. Prev Med 2012;55:163-170.

10 Melchart D, Eustachi A, Wellenhofer-Li Y, Doerfler W, Bohnes E: Individual health management - a comprehensive lifestyle counselling programme for health promotion, disease prevention and patient education. Forsch Komplementmed 2016;23:30-35.
Siegrist J, Marmot M: Health inequalities and the psychosocial environment - two scientific challenges. Soc Sci Med 2004;58:1463-1473.

12 Miller V, Yusuf S, Chow CK, Dehghan M, Corsi DJ, Lock K, Popkin B, Rangarajan S, Khatib R, Lear SA, Mony P, Kaur M, Mohan V, Vijayakumar K, Gupta R, Kruger A, Tsolekile L, Mohammadifard N, Rahman O, Rosengren A, Avezum A, Orlandini A, Ismail N, Lopez-Jaramillo P, Yusufali A, Karsidag K, Iqbal R, Chifamba J, Oakley SM, Ariffin F, Zatonska K, Poirier P, Wei L, Jian B, Hui C, Xu L, Xiulin B, Teo K, Mente A: Availability, affordability, and consumption of fruits and vegetables in 18 countries across income levels: findings from the Prospective Urban Rural Epidemiology (PURE) study. Lancet Glob Health 2016;4:e695703

3 Melchart D, Doerfler W, Eustachi A, Wellenhofer-Li Y, Weidenhammer W: The talent study: a multicentre randomized controlled trial assessing the impact of a 'tailored lifestyle self-management intervention' (talent) on weight reduction. BMC Obes 2015;2:38.
14 Walach H: Agenten statt Patienten (Editorial). Deutsche Zeitschrift für Akupunktur 2012;55:4-6.

15 Walach H, Loughlin M: Patients and agents - or why we need a different narrative: a philosophical analysis. Philos Ethics Humanit Med 2018;13:13.

16 Sullivan MD: The Patient as Agent of Health and Health Care. New York, Oxford University Press, 2016.

17 Hyland ME: The Origins of Health and Disease. Cambridge, Cambridge University Press, 2011.

18 Esch T: Selbstheilung als Teil der Medizin: Ein medizinisch-kultureller Blick auf die moderne Autoregulationsforschung. Dtsch Arzebl 2014;111:A22142220

19 Walach H: Complementary? Alternative? Integrative? Forsch Komplementmed 2010;17:215-216. 